\title{
High mobility group box 1 induces bone pain associated with bone invasion in a mouse model of advanced head and neck cancer
}

\author{
TOMOYA NAKAMURA ${ }^{1}$, TATSUO OKUI ${ }^{1}$, KAZUAKI HASEGAWA $^{1}$, \\ SHOJI RYUMON $^{1}$, SOICHIRO IBARAGI ${ }^{1}$, KISHO ONO ${ }^{1}$, YUKI KUNISADA ${ }^{1}$, \\ KYOICHI OBATA $^{1}$, MASANORI MASUI ${ }^{1}$, TSUYOSHI SHIMO ${ }^{2}$ and AKIRA SASAKI ${ }^{1}$
}

${ }^{1}$ Department of Oral and Maxillofacial Surgery and Biopathology, Okayama University Graduate School of Medicine, Dentistry and Pharmaceutical Science, Okayama 700-8525; ${ }^{2}$ Division of Reconstructive Surgery for Oral and Maxillofacial Region, Department of Human Biology and Pathophysiology, School of Dentistry, Health Sciences University of Hokkaido, Hokkaido 061-0293, Japan

Received July 16, 2020; Accepted September 11, 2020

DOI: $10.3892 / o r .2020 .7788$

\begin{abstract}
Advanced head and neck cancer (HNC) can invade facial bone and cause bone pain, thus posing a significant challenge to the quality of life of patients presenting with advanced HNC. The present study was designed to investigate HNC bone pain (HNC-BP) in an intratibial mouse xenograft model that utilized an HNC cell line (SAS cells). These mice develop HNC-BP that is associated with an expression of phosphorylated ERK1/2 (pERK1/2), which is a molecular indicator of neuron excitation in dorsal root ganglia (DRG) sensory neurons. Our experiments demonstrated that the inhibition of high mobility group box 1 (HMGB1) by short hairpin (shRNA) transduction, HMGB1 neutralizing antibody, and HMGB1 receptor antagonist suppressed the HNC-BP and the pERK1/2 expression in DRG. It was also observed that HNC-derived HMGB1 increased the expression of the acid-sensing nociceptor, transient receptor potential vanilloid 1 (TRPV1), which is a major cause of osteoclastic HNC-BP in DRG. Collectively, our results demonstrated that HMGB1 originating in HNC evokes HNC-BP via direct HMGB1 signaling and hypersensitization for the acid environment in sensory neurons.
\end{abstract}

\section{Introduction}

Head and neck cancer (HNC) frequently infiltrates and metastasizes bones (1), resulting in HNC-associated bone pain (HNC-BP) (2). Cancer pain is a prognostic factor of poor clinical outcomes (3). HNC-BP often reduces the ability

Correspondence to: Dr Tatsuo Okui, Department of Oral and Maxillofacial Surgery and Biopathology, Okayama University Graduate School of Medicine, Dentistry and Pharmaceutical Sciences, 2-5-1 Shikata-cho, Kita-ku, Okayama 700-8525, Japan E-mail:pphz1rke@okayama-u.ac.jp

Key words: head and neck cancer, bone pain, HMGB1, RAGE, sensory neuron to eat and swallow, thus posing a significant challenge to the quality of life of patients presenting with advanced HNC. The pathophysiology of bone pain associated with $\mathrm{HNC}$ is poorly understood (4), and HNC-BP is frequently inadequately treated.

Dead cells, dendritic cells, and cancer cells releases damage-associated molecular patterns (DAMPs), which initiate noninfectious inflammatory responses (5). Among the various DAMPs, high mobility group box 1 (HMGB1) was first discovered as a conserved non-histone DNA-binding protein and has been the most intensively studied (6). A 2015 study revealed that HMGB1 mediates inflammatory and immune reactions in the nervous system (7), and emerging evidence indicates that HMGB1 plays an essential role in neuropathic pain (8). Extracellular HMGB1 activates the receptor for advanced glycation end products (RAGE) and Toll-like receptor 4 (TLR4), promoting pain signals $(9,10)$. It was revealed that HMGB1 is overexpressed in the serum and tissues in several types of cancer, including breast cancer, malignant mesothelioma, and other malignancies $(11,12)$. However, the role of cancer-derived HMGB1 in HNC-BP remains unknown.

Cancer cells in bone metastasis and at bone invasion sites secrete significant amounts of growth factors, promoting osteoclastogenesis $(13,14)$. The best-known molecular pain inducer in HNC-BP is osteoclast-derived proton $\left(\mathrm{H}^{+}\right)(15)$. In the cancer bone microenvironment, cancer cells and osteoclasts secrete protons through the proton pump, creating an acidic microenvironment in the bone marrow (16). This environment activates $\mathrm{pH}$-sensitive sensory neurons via acid-sensing nociceptors such as transient receptor potential vanilloid 1 (TRPV1), eliciting bone pain (17). The findings of the present study provide initial evidence that HNC-derived HMGB1 directly activates sensory neurons and increases the expression of TRPV1, thus indirectly promoting acid-induced HNC-BP.

\section{Materials and methods}

Reagents. Puromycin dihydrochloride (\#P9620) was purchased from Sigma-Aldrich; Merck KGaA. TLR4 antagonist TAK-242 (\#13871) and RAGE antagonist FPS-ZM1 (\#11909) were purchased from Cayman Chemical Co. Chicken anti-HMGB1 
polyclonal antibody (\#326052233) was purchased from Shino-Test. Control shRNA plasmid-A (\#sc-108060), HMG-1 shRNA plasmid (\#sc-37982-SH), and anti-RAGE antibody (anti-mouse, monoclonal, sc-80652) were purchased from Santa Cruz Biotechnology, Inc. HMGB1 antibody (anti-mouse, monoclonal, GTX628834) was purchased from GeneTex, Inc. Anti-phospho-p44/42 MAPK antibody (p-ERK; anti-rabbit, monoclonal, \#4370), anti-p44/42 MAPK antibody (ERK; anti-rabbit, monoclonal, \#4695), horseradish peroxidase (HRP)-conjugated IgG antibody (goat anti-rabbit, monoclonal, \#7074), HRP-conjugated IgG antibody (goat anti-mouse, monoclonal, \#7076), and Alexa Fluor 488-conjugated IgG (H+L) $\mathrm{F}\left(\mathrm{ab}^{\prime}\right) 2$ fragment (goat anti-rabbit, monoclonal, \#4412) were purchased from Cell Signaling Technology, Inc. Anti-TLR4 antibody (anti-rabbit, polyclonal, \#ab13556), anti- $\beta$-actin antibody (anti-mouse, monoclonal, \#ab49900), anti-CGRP antibody (anti-goat, polyclonal, \#ab36001), and Alexa Fluor 647-conjugated IgG H\&L antibody (donkey anti-goat, monoclonal, \#ab150135) were purchased from Abcam.

Cell lines and culture conditions. The human HNC cell lines SAS (\#JCRB0260), HSC-2 (\#JCRB0622), HSC-3 (\#JCRB0623), HSC-4 (\#JCRB0624), OSC-19 (\#JCRB0198), and mouse fibroblast cell line 3T6 (\#JCRB9059) were obtained from the Human Science Resources Bank (Osaka, Japan). All of these cell lines were cultured in Dulbecco's modified Eagle's medium (DMEM) (Thermo Fisher Scientific, Inc.) supplemented with $10 \%$ heat-inactivated fetal bovine serum (FBS) and $1 \%$ penicillin-streptomycin. The rat DRG neuronal cell line 50B11 was kindly provided by Dr A. Hoke (Department of Neurology, School of Medicine, Johns Hopkins University, Baltimore, MD, USA) and cultured in neurobasal medium. MLO-A5 cells provided by Dr T. Bellido (Department of Anatomy and Cell Biology, School of Medicine, Indiana University, Indianapolis, IN, USA) and primary mouse osteoblast cells (OBC12) (Cosmo Bio, Tokyo) were cultured in $\alpha$-MEM (minimal essential medium) containing 5\% FBS. Cells of the mouse macrophage cell line RAW264.7 were cultured in $\alpha$-MEM containing $10 \%$ FBS.

Rat DRG cells were obtained from Lonza Japan and cultured according to the supplier's instructions. All cell lines were cultured in an atmosphere of $5 \% \mathrm{CO}_{2}$ at $37^{\circ} \mathrm{C}$.

Immunohistochemical analysis. We analyzed the expression of HMGB1 in HNC tissue and a normal tissue microarray (\#OR601d; US Biomax). The antigen was activated by cooking in a citric acid solution. For the immunohistochemical analysis, the specimens were incubated with anti-HMGB1 antibody (dilution 1:200) overnight at $4^{\circ} \mathrm{C}$. The slides were then treated with a streptavidin-biotin complex (EnVision System labeled polymer, HRP; Dako; Agilent Technologies, Inc.) for $60 \mathrm{~min}$ at a dilution of 1:100. The immunoreaction was visualized with the use of a DAB substrate-chromogen solution (Dako Cytomation Liquid DAB Substrate Chromogen System, Agilent Technologies, Inc.). The cells were counted using a light microscope and evaluated.

Analysis of HMGB1 expression in SAS cells. SAS cells were transfected with $5.0 \mu \mathrm{g}$ control short hairpin (sh)RNA or HMGB1 shRNA with the use of 4D-Nucleofector ${ }^{\mathrm{TM}}$
(Lonza Group, Ltd.). Two days later, the cells were cultured in DMEM + 10\% FBS for 5 days in the presence of $1.6 \mu \mathrm{g} / \mathrm{ml}$ puromycin dihydrochloride for the selection of cells that stably expressed the shRNAs.

The hairpin sequence was as follows: GATCCAAGCACC CAGATGCTTCAGTTTCAAGAGAACTGAAGCATCTGG GTGCTTTTTTT. The corresponding siRNA sequences were sense, AAGCACCCAGAUGCUUCAGUtt and antisense, ACUGAAGCAUCUGGGUGCUUtt. All sequences are provided in $5^{\prime} \rightarrow 3^{\prime}$ orientation.

Cell proliferation assay. SAS cells were plated in 24-well plates at $1.5 \times 10^{4}$ cells per well. Their number was counted $72 \mathrm{~h}$ later with a TC20 automated cell counter according to the manufacturer's instructions (Bio-Rad Laboratories, Inc.).

Western blot analysis. The cell lysates were mixed with $4 \mathrm{X}$ Laemmli sample buffer (Bio-Rad Laboratories, Inc.) and heated at $95^{\circ} \mathrm{C}$ for $5 \mathrm{~min}$. The samples were electrophoresed on 4-12\% SDS-PAGE gels, and the proteins were transferred onto PVDF membranes (Bio-Rad Laboratories, Inc.). The membranes were incubated with primary and secondary antibodies according to the ECL chemiluminescence protocol (RPN2109; Amersham Biosciences) to detect secondary antibody binding. Antibodies against HMGB1 (1:1,000), TLR-4 (1:500), RAGE (1:1,000), p-ERK (1:1,000), ERK (1:1,000), TRPV1 $(1: 1,000)$, and $\beta$-actin $(1: 10,000)$ were used as the primary antibodies. HRP-conjugated anti-rabbit antibody $(1: 2,000)$ and HRP-conjugated anti-mouse antibody $(1: 2,000)$ were used as the secondary antibodies.

We evaluated the effects of three redox forms of HMGB1 on sensory neuronal excitation. Cells of the DRG neuronal cell line $50 \mathrm{~B} 11$ were cultured on 6-well plates $\left(5 \times 10^{4} /\right.$ well) in DMEM and incubated for $24 \mathrm{~h}$ after the addition of each isoform of HMGB1 (HMGB1 Isoform Kit, \#HM-030, HMGBiotech). The protein was then collected. A ChemiDoc MP system (Bio-Rad Laboratories, Inc.) was used for the analysis of the western blots.

Sensory neuron fiber sprouting assay. DRG cells were plated on 48 -well plates $\left(1 \times 10^{4} /\right.$ well $)$ in neuron growth medium for $24 \mathrm{~h}$. The conditioned medium of SAS, short hairpin (sh)-control SAS, and sh-HMGB1 SAS cells was added to each well at $30 \%$ of the total medium volume. The conditioned medium had been collected after the incubation of $5.0 \times 10^{6}$ of each cell in DMEM plus 2\% FBS for $24 \mathrm{~h}$.

We also evaluated an HMGB1 neutralizing antibody which was applied to the wells with conditioned medium of SAS at the following concentrations: Anti-HMGB1 polyclonal antibody (100 ng/ml). DRG fibers were visualized by calcein acetoxymethyl (AM) staining on Day 5. DRG neuronal fibers were observed with a Keyence microscope (magnification, x200) (BZ-8100; Osaka, Japan).

Animal experiments. We established a mouse model of bone invasion by human $\mathrm{HNC}$ in 7-week-old male BALB/c nude mice (each group, $\mathrm{n}=8$; total, $\mathrm{n}=56$; mean body weight, $24.3 \mathrm{~g}$; Charles River Laboratories, Yokohama, Japan) by the inoculation of $1 \times 10^{5}$ SAS cells (parental, sh-control, sh-HMGB1) with a 29-gauge needle into the bone marrow space of the right tibial edge of the mouse under anesthesia with $0.4 \mathrm{mg} / \mathrm{kg}$ of 
medetomidine, $4.0 \mathrm{mg} / \mathrm{kg}$ of midazolam, and $5.0 \mathrm{mg} / \mathrm{kg}$ of butorphanol. The sham procedure was only a puncture with a 29-gauage needle into the right tibial cavity. Body condition scoring was applied and body weight was monitored daily. Mice were maintained in housing conditions at a temperature of $23 \pm 1^{\circ} \mathrm{C}$, humidity of $40-80 \%$ and lighting time of $12 \mathrm{~h}$ from 8 am to $8 \mathrm{pm}$. Food and water were taken freely.

Mechanical hyperalgesia was evaluated every other day on postoperative day (POD)1-9 in each group of mice. We also evaluated the effects of the HMGB1 neutralizing antibody and receptor antagonist. SAS-inoculated mice were treated with intraperitoneal injections of anti-HMGB1 polyclonal antibody, RAGE antagonist FPS-ZM1, and TLR4 antagonist TAK-242 on POD10, and then we performed the assay every $6 \mathrm{~h}$ over a $24-h$ period. The mice were individually placed in a cage with a mesh floor, over a moveable pressure-stimulating filament. The filament was positioned under the center of the hind paw, and the time (sec) from stimulus onset to withdrawal was recorded. Previously we reported that SAS tumor progression in the tibia promotes bone destruction and fracture around POD20 (18). In this research we evaluated the direct cancer bone pain before fracture. On POD10, the mice underwent cardiac blood collection under anesthesia with $0.4 \mathrm{mg} / \mathrm{kg}$ of medetomidine, $4.0 \mathrm{mg} / \mathrm{kg}$ of midazolam and $5.0 \mathrm{mg} / \mathrm{kg}$ of butorphanol (i.p), followed by cervical dislocation. Ipsilateral L4-L5 DRGs and the right tibia were then harvested. The criteria of humane endpoints for euthanasia was loss of $>20$ percent of body weight compared to the age-matched controls. Death of the animal was verified by cessation of cardiovascular and respiratory movements. All of the animal experimental protocols were approved by the Ethics Review Committee for Animal Experimentation of the Okayama University Graduate School of Medicine and Dentistry (OKU-2018701, 20/Nov/2018).

In vivo analysis of $H N C-B P$. We evaluated the mechanical hyperalgesia in the mice with the use of a Dynamic Plantar Aesthesiometer (\#37450; Ugo Basile), which measures an animal's withdrawal latency to non-painful pressure at the proximal half of the plantar surface of the ipsilateral hind paw, and we applied an increasing force $(2.75 \mathrm{~g} / \mathrm{sec})$. Prior to this examination, the mice were allowed to acclimate to the testing environment for $30 \mathrm{~min}$. The testing environment consisted of translucent plastic-walled individual chambers with a metal mesh bottom. When the mouse withdrew its hind paw, the mechanical stimulus stopped automatically and the latency was recorded by the device precisely in $0.1-\mathrm{sec}$ increments. The test was performed every other day on POD1-9 in the sham, parental, sh-control and sh-HMGB1 groups. For the evaluations of the effects of the HMGB1 neutralizing antibody and receptor antagonist, intraperitoneal injections of anti-HMGB1 antibody (2 mg/kg), FPS-ZM1 (10 mg/kg), and TAK-242 $(10 \mathrm{mg} / \mathrm{kg})$ were respectively conducted for SAS-inoculated mice, and the assays were performed every $6 \mathrm{~h}$ over the $24-\mathrm{h}$ period on POD10. The concentration of agents used in vivo are referenced from previous studies (19-21).

In vivo radiography and the measurement of osteolytic lesion areas. Osteolytic bone destruction was assessed on radiographs. The bones were placed against films $(22 \times 27 \mathrm{~cm}$; Fuji Industrial Film FR; Fuji Photo Film) and exposed to soft
X-rays at $35 \mathrm{kV}$ for $15 \mathrm{sec}$ with the use of a Sofron apparatus (Sofron).

HMGB1 concentration measurement. The HMGB1 concentrations in the mouse tibia, whole blood serum, and conditioned medium were evaluated by enzyme-linked immunosorbent assay (ELISA). Both ends of the tibias were cut, and the bone marrow serum was extracted by centrifugation. The culture supernatant had been collected after the incubation of $5.0 \times 10^{6}$ parental, sh-control and sh-HMGB1 SAS cells in DMEM plus $2 \%$ FBS for $24 \mathrm{~h}$. Each concentration of HMGB1 was measured by the HMGB1 ELISA Kit (HMGB1 ELISA Kit II; Shino-Test). The protocol of the manufacturer was followed.

DRG processing. Corrected DRGs were homogenized in RIPA lysis buffer with $1 \mathrm{mMPMSF}$ and phosphatase inhibitor $\left(\mathrm{Na}_{3} \mathrm{VO}_{4}\right.$ and $\mathrm{NaF}$ ) added. The lysate was centrifuged at 15,000 $\mathrm{x} \mathrm{g}$ for 5 min at $4^{\circ} \mathrm{C}$, and the supernatant was collected as total protein. Some of the collected DRGs were fixed in $10 \%$ neutral-buffered formalin and then embedded in paraffin. Western blotting and immunofluorescence were performed using these DRGs.

Immunofluorescence analysis. We conducted an immunofluorescence analysis to determine the expressions of $\mathrm{p}$-ERK in DRGs from each group of mice. The specimens were incubated with $3 \%$ bovine serum albumin-phosphate buffered saline (BSA-PBS) blocking solution, and then with p-ERK antibody (dilution 1:200) and anti-CGRP antibody (dilution 1:200) overnight at $4^{\circ} \mathrm{C}$ as primary antibodies, followed by Alexa Fluor 488 anti-rabbit IgG (dilution 1:1,000) or and Alexa Fluor 647 anti-goat IgG $(1: 1,000)$ as secondary antibodies. Nuclei were counterstained with Fluoroshield mounting medium with DAPI (\#ab104139; Abcam).

Statistical analyses. The data were analyzed using an unpaired Student's t-test for comparisons of two groups and by performing a one-way analysis of variance (ANOVA) and a post hoc Tukey's test for the analysis of multiple group comparisons with Graph Pad Prism, ver. 7.0 (GraphPad Software, Inc.). The results are expressed as the mean \pm standard deviation (SD). Probability (P)-values $<0.05$ were considered significant.

\section{Results}

HMGB1 expression in the human HNC samples. Fig. 1 provides a representative histologic pattern of normal oral tissue and HNC tissue. HMGB1 was highly expressed in the HNC patient samples compared to the normal head and neck samples (Fig. 1A and B). The ratios of HMGB1-positive nuclei in each HNC sample and the normal oral tissues were the same, but the ratio of cytoplasm HMGB1-positive cells was much higher in the HNC tissue compared to the normal oral tissue (Fig. 1C).

Effect of HNC-derived HMGBI on neurite sprouting. To determine whether HNC cells express HMGB1 in vitro, we performed a western blot analysis of HMGB1 expression in the HNC cell lines. As shown in Fig. 2A, the results of the western blot analysis revealed high expression of HMGB1 in the SAS cells. To examine the role of cancer-derived HMGB1 


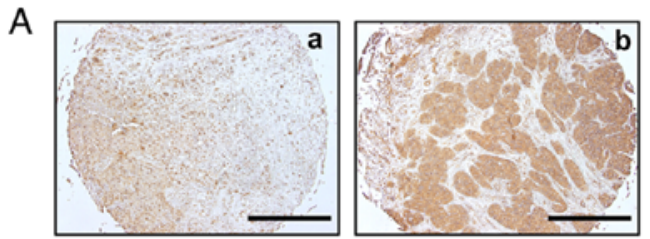

B

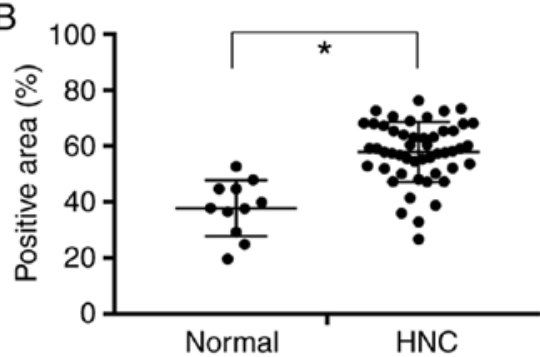

C

(\%)

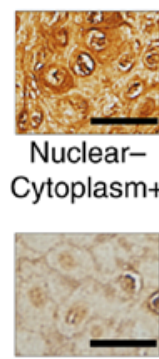

Nuclear+

Cytoplasm-

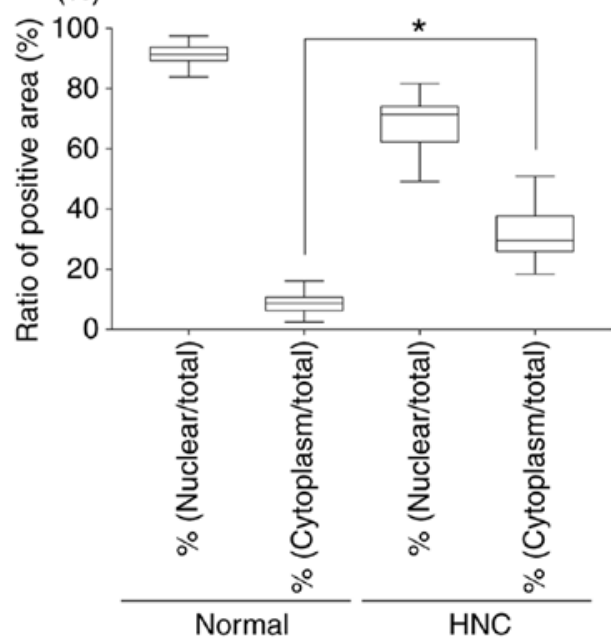

Figure 1. Expression of HMGB1 in HNC and head and neck normal tissues. (A) Immunohistochemistry analysis of HMGB1 in head and neck normal tissue (a) and HNC tissue (b). Scale bar, $1 \mathrm{~mm}$. (B) Scatterplot of the HMGB1-positive areas in the head and neck normal tissues $(\mathrm{n}=11)$ and $\mathrm{HNC}$ $(n=70)$. Error bars: Mean \pm SD. There was a significantly increased expression of HMGB1 in the HNC samples ( $\mathrm{P}<0.01)$. (C) The ratio of nucleic or cytoplasmic HMGB1-positive cells in the normal tissues and HNC tissues. Scale bar, $50 \mu \mathrm{m}$. Error bars: Mean \pm SD. There was a significantly increased expression of HMGB1 in the cytoplasm of the HNC samples. ${ }^{*} \mathrm{P}<0.01$. HMGB1, high mobility group box 1 ; $\mathrm{HNC}$, head and neck cancer.

in neurite sprouting in vitro, we first evaluated the expression of HMGB1 in sensory neurons. Fig. 2B demonstrates that the bone and neuronal cell lines expressed both RAGE and TLR4.

We next cultured the DRG sensory neuron cells in neuron growth medium containing conditioned medium of SAS (CM) with or without HMGB1 neutralizing antibody $(\mathrm{Ab})$ to evaluate sensory neuron axis sprouting. Fig. $2 \mathrm{C}$ and $\mathrm{D}$ shows that the cultures with SAS CM exhibited increased neuron lengths, and the HMGB1 neutralizing antibody suppressed that effect.

HMGB1 neutralizing antibody suppresses $H N C-B P$ and sensory nerve excitation in vivo. The mouse tibias injected with SAS cells developed aggressive proliferation of SAS cells in the bone marrow and bone destruction (Fig. 3A). To evaluate the role of HMGB1 in SAS-induced HNC-BP, we investigated SAS injection-induced mechanical hyperalgesia in the mouse bone marrow after the injection of SAS cells. At POD10, we observed that the treatment with the HMGB1 neutralizing antibody significantly reduced hyperalgesia compared to the parental SAS cell-injected mice (Fig. 3B).

In parallel with the HNC-BP results, the DRGs from the SAS-injected mice demonstrated an increased expression of phosphorylated (p)-ERK1/2, which is a molecular indicator of neuron excitation. In contrast, the DRGs from the sham-operated mice and the HMGB1 neutralizing antibody-treated mice showed decreased p-ERK1/2 expression in the western blot analysis (Fig. 3C).

RAGE and the TLR4 antagonist suppress the sensory nerve excitation and HNC-BP in vivo. To evaluate the role of the HMGB1 receptor in SAS-induced HNC-BP, we investigated SAS injection-induced mechanical hyperalgesia. Treatment with the RAGE antagonist FPS-ZM1 or TLR4 antagonist TAK-242 both significantly reduced hyperalgesia compared to the SAS cell-injected mice (Fig. 4A). As expected, the DRGs from the mice administered the RAGE antagonist or TLR4 antagonist showed significantly decreased p-ERK1/2 expression in the western blot and immunofluorescence analyses (Fig. 4B and C). Calcitonin gene-related peptides (CGRP) are neuropeptides expressed in sensory nerve, and are a positive control of sensory neurons.

Reduction in HMGBI in SAS cells decreases sensory nerve sprouting. Next, to investigate the role of cancer-derived HMGB1 in HNC-BP, we introduced an shRNA plasmid targeting HMGB1 into SAS cells by an electroporation system. As shown in Fig. 5A, a $60 \%$ suppression of the expression of HMGB1 protein in SAS was observed in the shHMGB1-transfected group (sh-HMGB1) compared to the parental SAS cells and control shRNA (sh-control) plasmid-introduced group. The proliferation ability of the HMGB1-knockdown SAS cells did not differ significantly from that of the sh-control SAS cells (Fig. 5B). HMGB1 in conditioned medium tended to be decreased in the shHMGB1-transfected SAS cells (Fig. 5C). This conditioned medium promoted significantly less sensory neuron sprouting in the in vitro cultures (Fig. 5D and E).

$H M G B 1$ derived from $H N C$ promotes $H N C-B P$ and the excitation of sensory nerves in vivo. To evaluate cancer-derived HMGB1, we injected the parental, sh-control, and sh-HMGB1 SAS cells into mouse tibial bone marrow and determined the systemic and local serum HMGB1 concentrations on POD10. Tumor area of the SAS parental (Fig. 6A-a), sh-control (Fig. 6A-b) and sh-HMGB1 (Fig. 6A-c) cell groups are shown. At a point on POD10, there were no significant differences in regards to tumor burden in the tibia and body weight between the HMGB1-knockdown SAS vs. parental and sh-control SAS cell-injected mice (Fig. 6A-d and -e). There were no significant between-group differences in the HMGB1 concentrations in the cardiac tissues (Fig. 6B-a). Compared to the parental SAS and sh-control SAS cell-injected mice, the injection of sh-HMGB1 SAS cells significantly decreased the HMGB1 levels in the bone marrow (Fig. 6B-b). In parallel with these results, HMGB1 knockdown significantly reduced hyperalgesia compared to the parental SAS- and sh-control SAS cell-injected mice on POD5, 7 and 9 (Fig. 6C). Similar to the HNC-BP results, the DRGs 
A

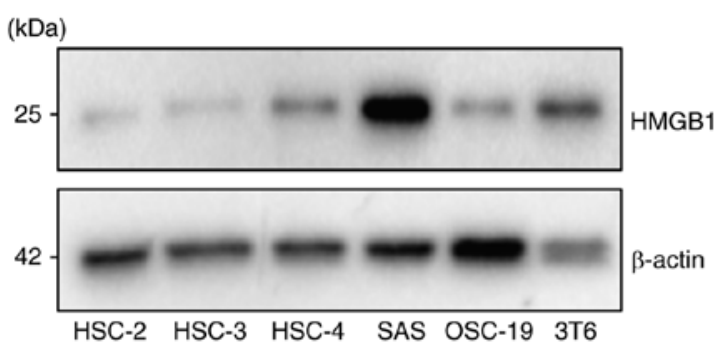

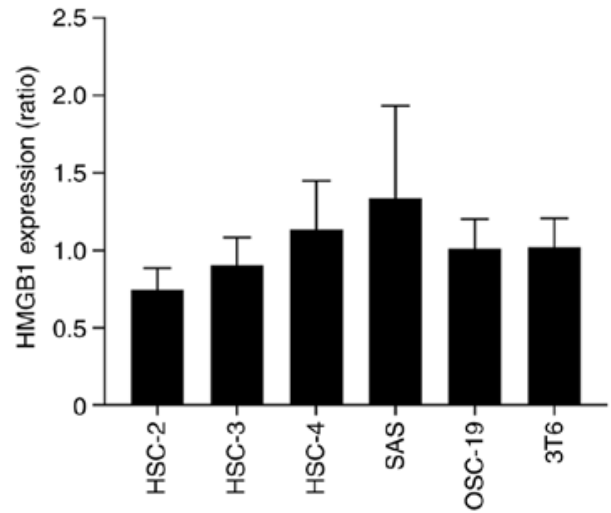

$\mathrm{B}(\mathrm{kDa})$
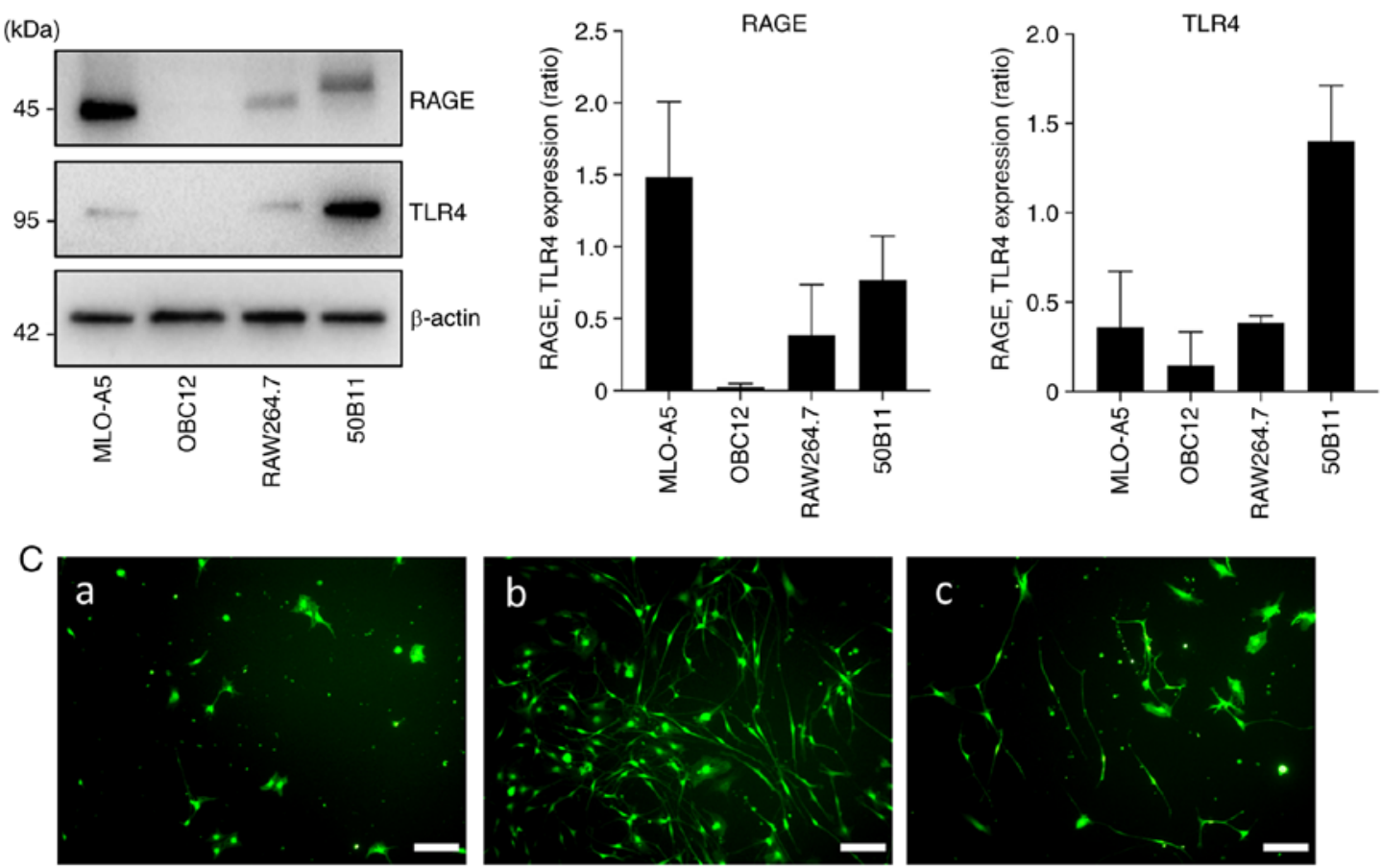

Control
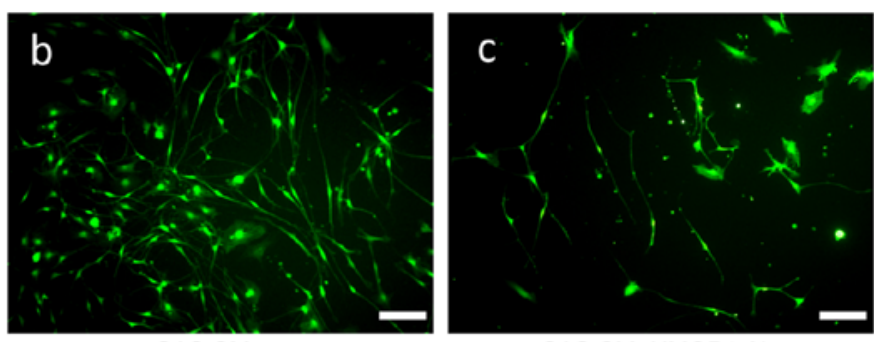

SAS CM+HMGB1 Ab

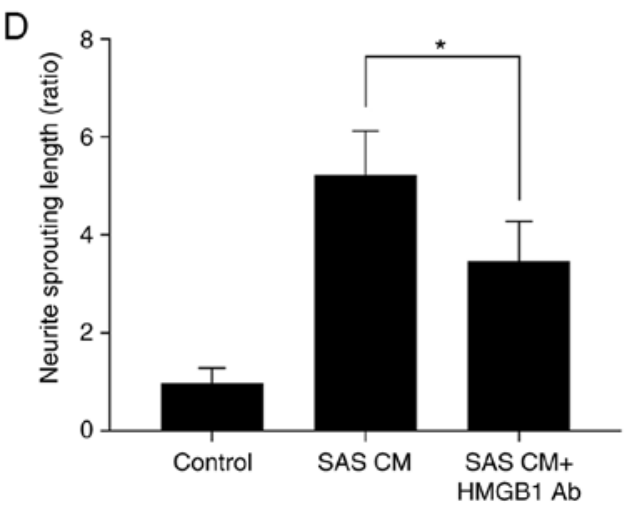

Figure 2. Effects of HMGB1 on neurite induction and outgrowth. (A) Expression of HMGB1 in HNC cell lines (HSC-2, HSC-3, HSC-4, SAS, OSC-19) and mouse fibroblast cell line (3T6) by western blot analysis. The right panel shows the quantification ( $\mathrm{n}=3$ ). (B) Expressions of RAGE and TLR4 in each cell line: Osteocytes (MLO-A5), osteoblasts (OBC12), macrophages prior to osteoclast differentiation (RAW264.7), and neurons (50B11). The right panel shows the quantification $(n=3)$. (C) Neurite outgrowth from primary sensory neuron cells in neuron growth medium containing conditioned medium of SAS (CM) with/without HMGB1 neutralizing antibody. (a) Control, (b) SAS CM, and (c) SAS CM with HMGB1 antibody (Ab) for 5 days, labeled with calcein AM. Scale bar, $100 \mu \mathrm{m}$. (D) Quantitative data of neurite length shown in C. Error bars: Mean \pm SD; ${ }^{*} \mathrm{P}<0.01$ vs. SAS CM. HMGB1, high mobility group box 1; HNC, head and neck cancer; RAGE, advanced glycation end products; TLR4, Toll-like receptor 4.

from the parental SAS or sh-control SAS cell-injected mice demonstrated an increased expression of p-ERK1/2, which is a molecular indicator of neuron excitation. In contrast, the
DRGs from the HMGB1-knockdown SAS cell-injected mice showed decreased p-ERK1/2 expression in the western blot and immunofluorescence analyses (Fig. 6D and E). 


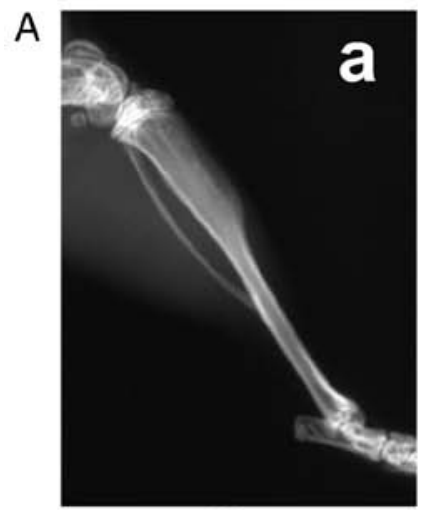

Sham

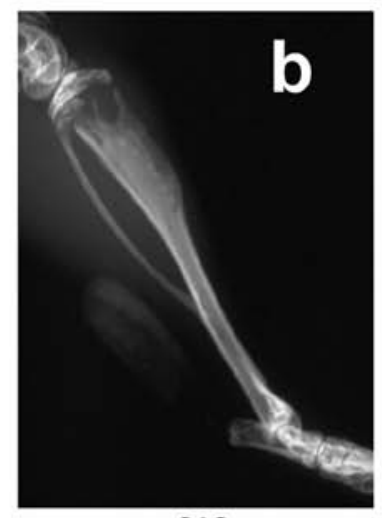

SAS

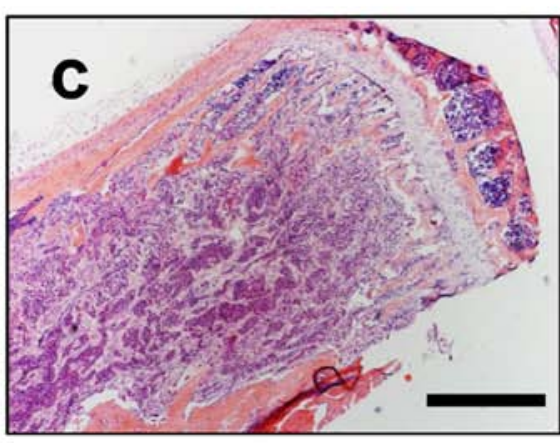

B

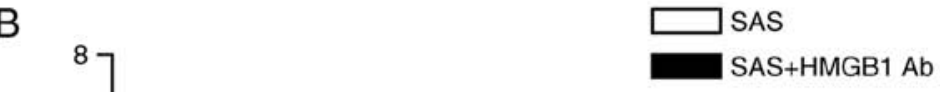

C a $(\mathrm{kDa})$
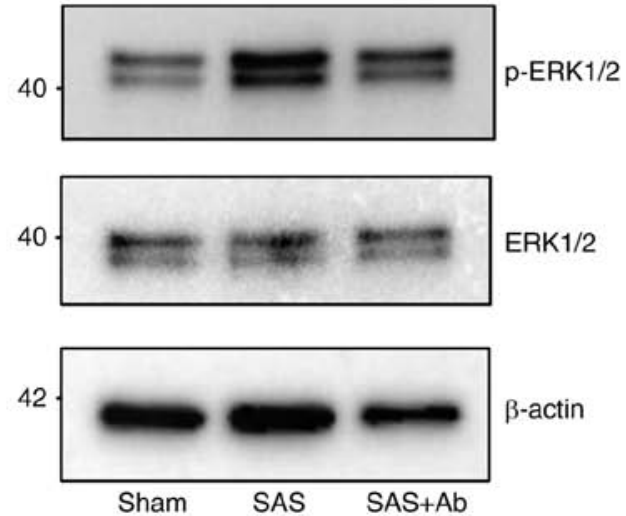

b

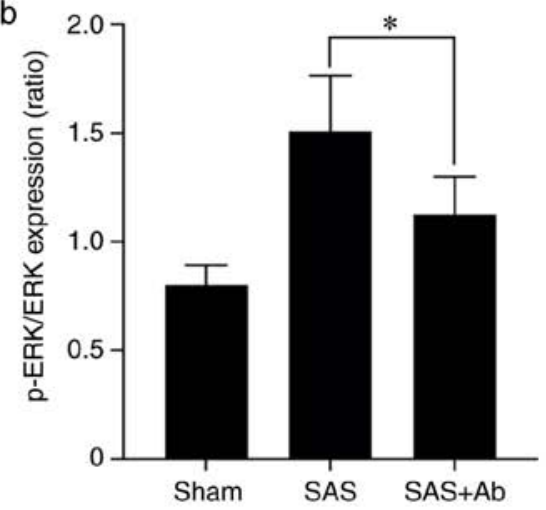

Figure 3. Contributions of HMGB1 to HNC-BP and sensory nerve excitation in vivo. (A) X-ray showing bone resorption of SAS cell-injected mouse tibia on POD10. (a) X-ray image of sham operated mouse, (b) X-ray image of SAS cell-injected mouse and (c) SAS cells colonization in bone marrow (hematoxylin and eosin staining). Scale bar, $1 \mathrm{~mm}$. (B) Mechanical hyperalgesia of SAS-injected mice compared to the mouse group treated with HMGB1 neutralizing antibody $(\mathrm{Ab})(2 \mathrm{mg} / \mathrm{kg})$. The test was performed over the $24-\mathrm{h}$ time course analysis POD10 $(\mathrm{n}=8)$. Error bars: Mean \pm SD. "P<0.01 vs. SAS group. (C) Excitation of sensory nerves determined by phosphorylated (p)-ERK1/2 expression in dorsal root ganglia (DRG) by western blot analysis. (a) Representative blot and (b) quantification with densitometry of p-ERK/ERK ( $n=3$ ). Error bars: Mean \pm SD. " $\mathrm{P}<0.05$ vs. SAS group. HMGB1, high mobility group box 1; HNC, head and neck cancer; HNC-BP, HNC-associated bone pain; POD, postoperative day.

The three redox forms of $H M G B 1$ have different roles in sensory neuron excitation. HMGB1 contains three conserved cysteine residues: Cys23, Cys45 and Cys106. The functions of HMGB1 depend on redox-sensitive cysteine residues (Cys23, Cys45 and Cys106) of the protein. HMGB1 has at least three redox forms with different biological functions: i) All-thiol HMGB1 (all three cysteine residues in the thiol state), ii) 'disulfide HMGB1' (an intramolecular disulfide bridge between Cys23 and Cys45; Cys106 in the thiol state), and ii) 'Terminal oxidized HMGB1' (all three cysteines in the hyperoxidized sulfonic acid state). The western blot results indicated that all-thiol HMGB1 and disulfide HMGB1 directly stimulated DRG sensory neuron cells as determined by a significant increase in p-ERK. Furthermore, 


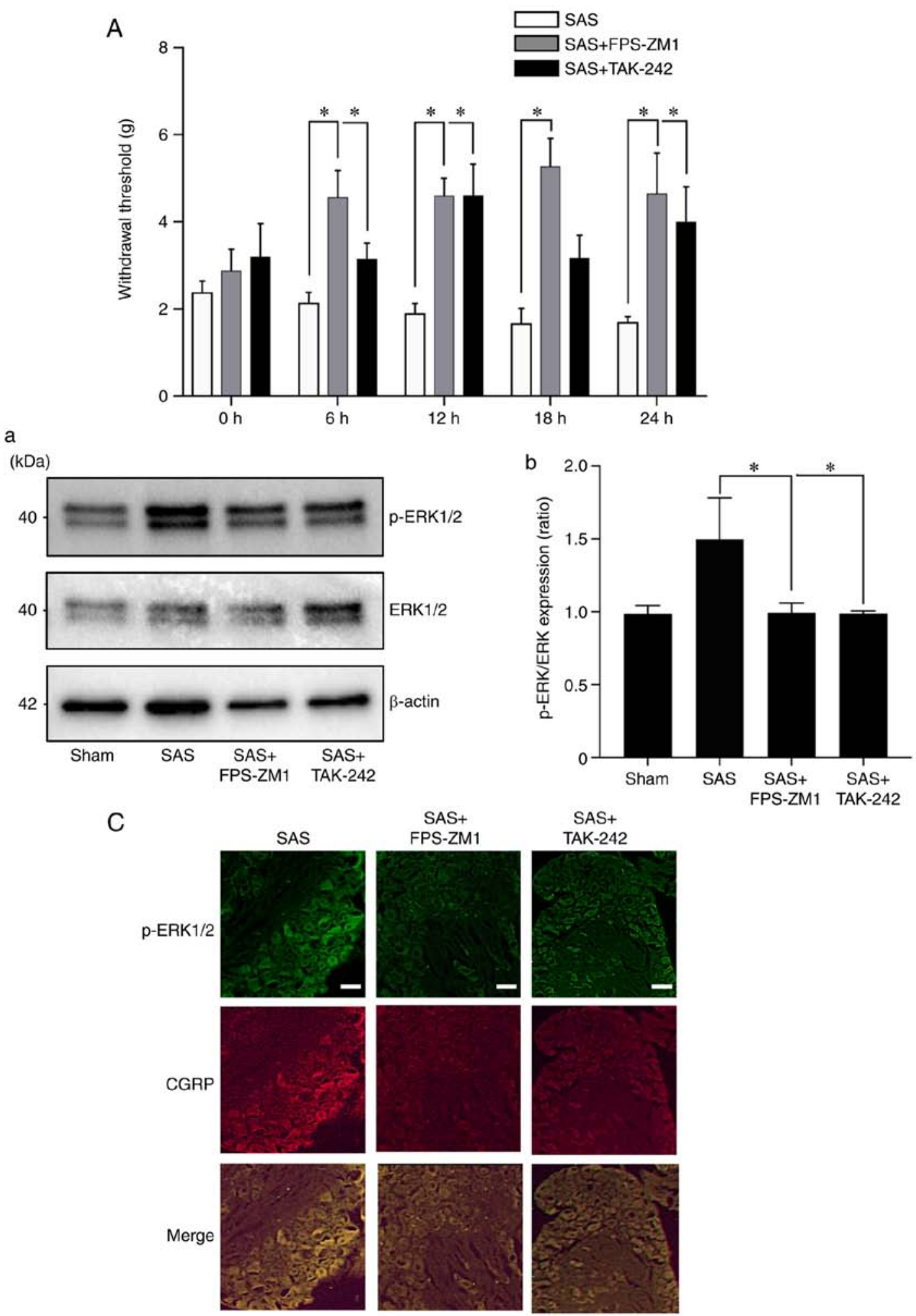

B a

Figure 4. Effects of the HMGB1 receptor antagonists in HNC-BP in vivo. (A) The 24-h time course analysis of mechanical hyperalgesia following treatment with vehicle (0.1\% DMSO in PBS), RAGE antagonist FPS-ZM1, or TLR4 antagonist TAK-242 (both $10 \mathrm{mg} / \mathrm{kg}$ ) in SAS-injected mice on POD10 ( $=8$ ). Error bars: Mean \pm SD. ${ }^{*} \mathrm{P}<0.05$ vs. the SAS group. (B) Expression of phosphorylated (p-)ERK1/2 in the dorsal root ganglia (DRG) of the mice shown in panel A by western blot analysis. (a) Representative blot and (b) quantification with densitometry of p-ERK/ERK (n=3). Error bars: Mean \pm SD. " $\mathrm{P}<0.05$ vs. the SAS group. (C) Immunofluorescence analysis of DRGs. Upper panels, p-ERK1/2 (green); middle panels, CGRP (red); lower panels, merged. Scale bar, $50 \mu \mathrm{m}$. HMGB1, high mobility group box 1; HNC, head and neck cancer; HNC-BP, HNC-associated bone pain; CGRP, calcitonin gene-related peptide.

they both sensitized the acid-induced stimulation by significantly increasing the TRPV1 expression, and also HMGB1 neutralizing antibody addition suppressed TRPV1 expression (Fig. 7A and B).

\section{Discussion}

Bone-invasive cancer including head and neck cancer (HNC), breast cancer, and multiple myeloma frequently invade 
$A_{(\mathrm{kDa})}$

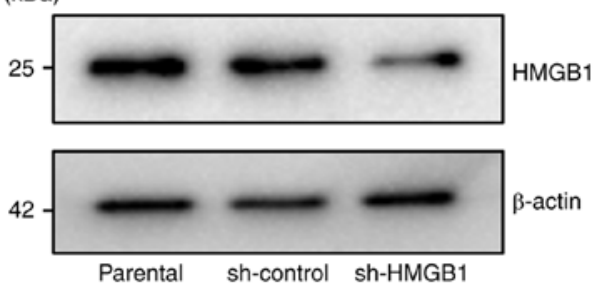

Parental sh-control sh-HMGB1

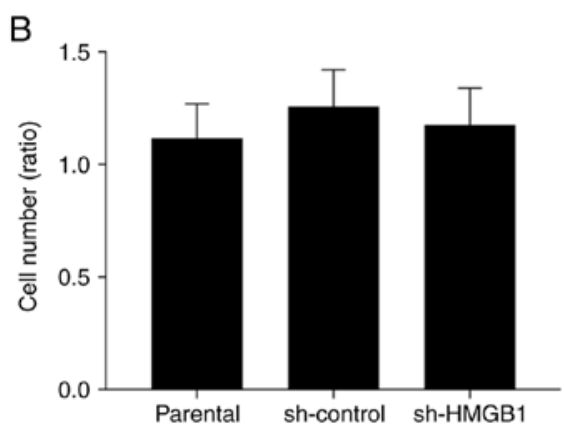

$\mathrm{D}$
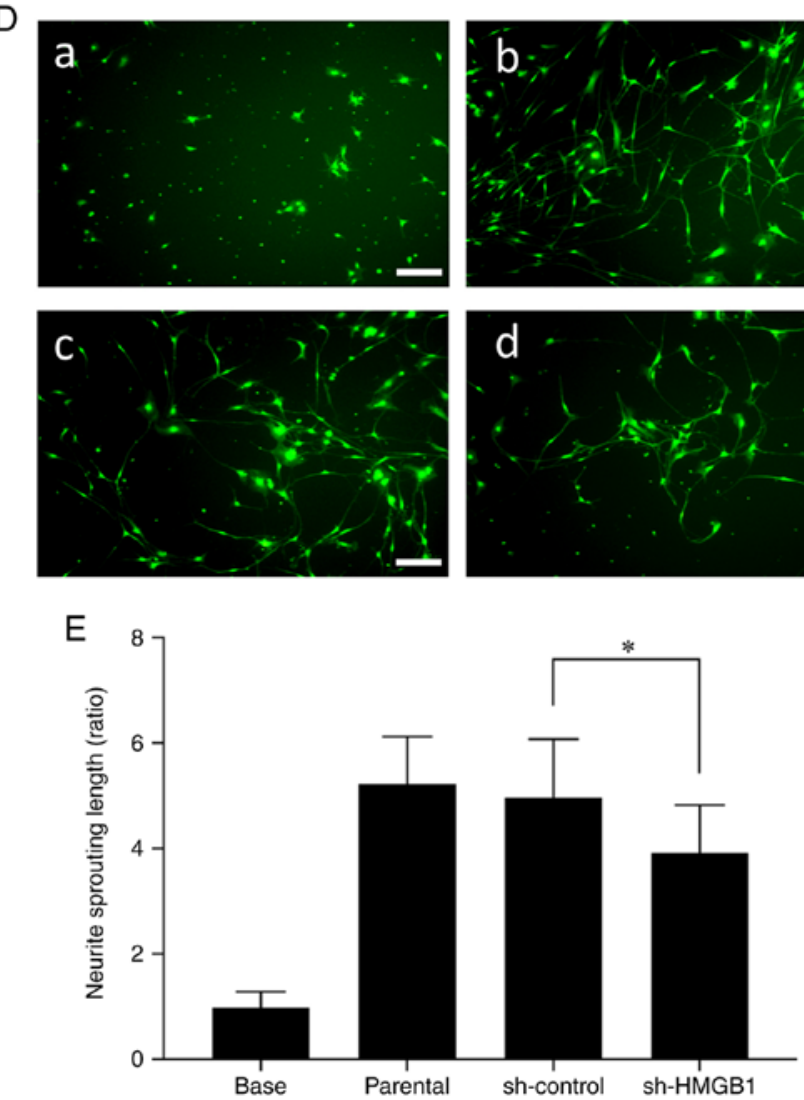

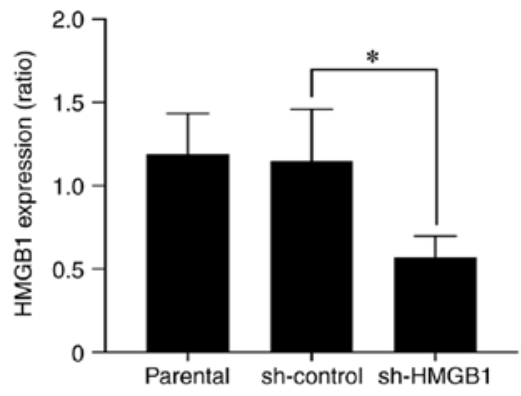

C $(\mathrm{ng} / \mathrm{ml})$
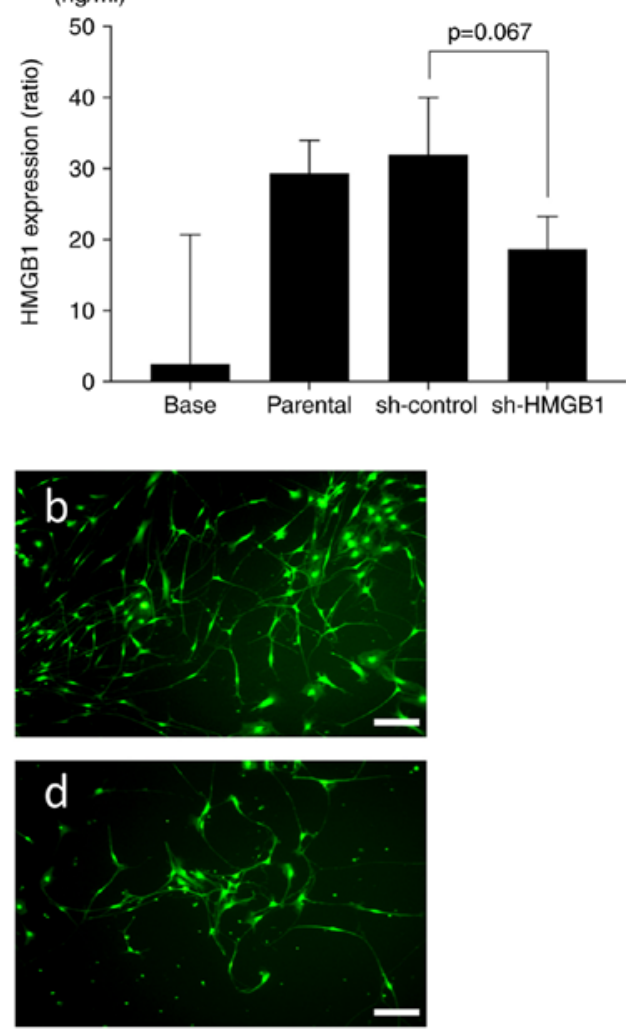

sh-HMGB1

Figure 5. Effect of the reduction in HMGB1 protein in the HNC SAS cells. (A) Expression of HMGB1 in the SAS cells. SAS cells stably transfected with control shRNA (sh-control) and HMGB1 shRNA (sh-HMGB1) and non-transfected cells (parental) were analyzed by western blot analysis for HMGB1 expression. The right panel shows their quantification ( $\mathrm{n}=3$ ). Error bars: Mean \pm SD. ${ }^{*} \mathrm{P}<0.05$ vs. sh-control. (B) Proliferation assay. Parental, sh-control, and sh-HMGB1 cells were cultured for $72 \mathrm{~h}$, and then the number of cells was counted $(\mathrm{n}=3)$. There was no significant difference between the cells in regards to proliferation ability. Error bars: Mean \pm SD. (C) HMGB1 concentrations in the conditioned medium of each SAS group were determined by ELISA analysis ( $\mathrm{n}=3$ ). There was no significant different between the sh-control and sh-HMGB1, but a decline in HMGB1 in culture supernatants was observed in sh-HMGB1 compared to sh-control ( $\mathrm{P}=0.067)$. (D) Neurite sprouting from DRG sensory neuron cells cultured with the conditioned medium of each group of SAS: (a) control (b) parental CM (c) sh-control CM (d) sh-HMGB1 CM for 5 days, labeled with calcein AM. Scale bar, $100 \mu \mathrm{m}$. (E) Quantitative data of neurite length shown in D. Error bars: Mean $\pm \mathrm{SD}$; ${ }^{*} \mathrm{P}<0.01$ vs. sh-control CM. HMGB1, high mobility group box 1; HNC, head and neck cancer.

and metastasize to bone, promoting bone pain. Cancer cells in bone marrow release various cytokines and growth factors (13), and these cytokines contribute to the activation of sensory neurons, leading to cancer-induced bone pain (22). 
A

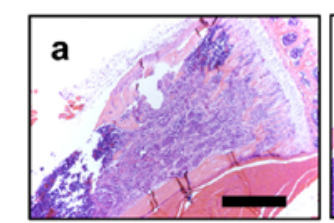

e

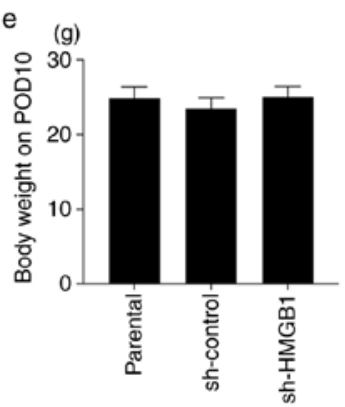

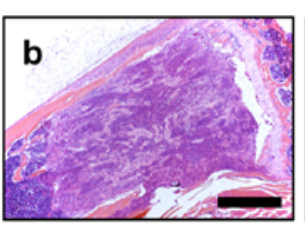

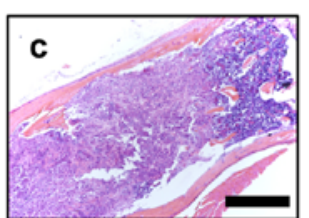

B

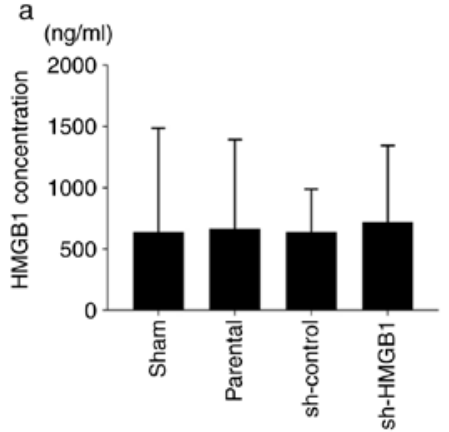

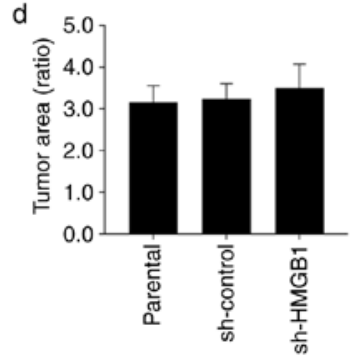

b

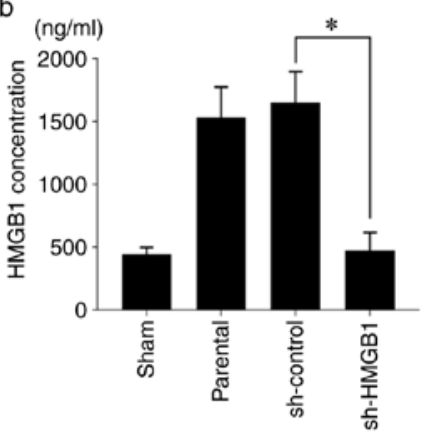

C

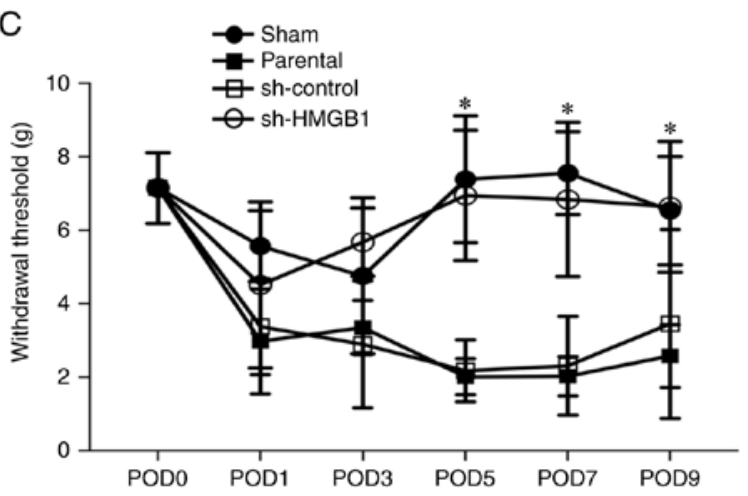

E
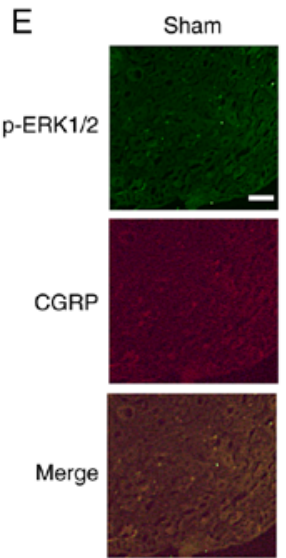
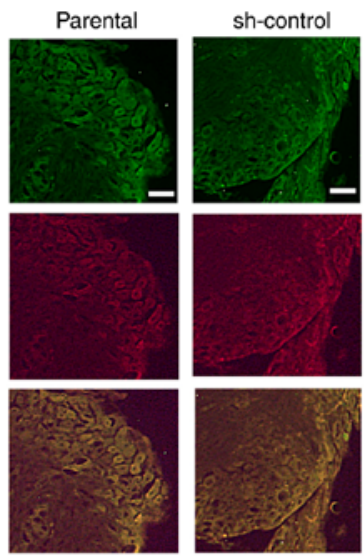
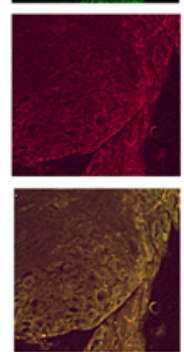

$\mathrm{D}$ a (kDa)
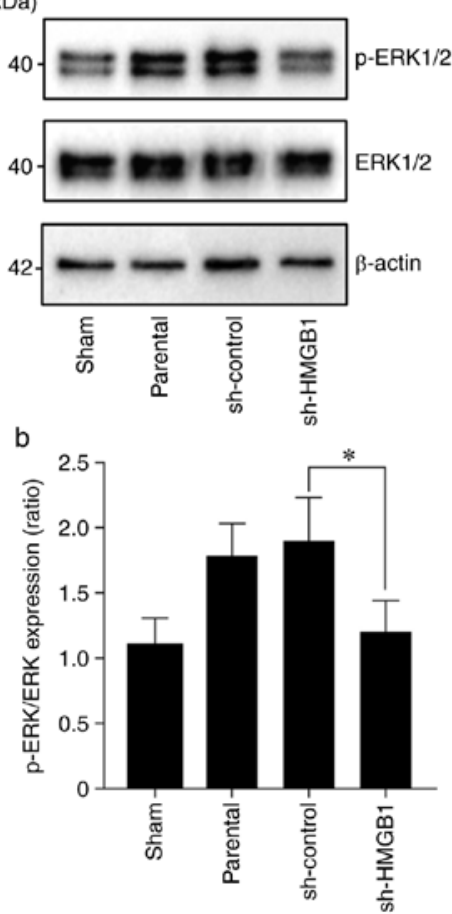

Figure 6. Effect of the reduction of HMGB1 on HNC-BP and sensory neuron excitation in vivo. (A) Tumor area of SAS parental, sh-control and sh-HMGB1 groups in tibia bone marrow (hematoxylin and eosin) at x40 magnification. Scale bar, $1 \mathrm{~mm}$. (a) Parental, (b) sh-control and (c) sh-HMGB1 groups. (d) Quantitative data $(n=4)$. There was no significant difference between each of them. (e) Body weight of each group on POD10 (n=8). (B) HMGB1 concentrations in cardiac blood samples and tibia bone marrow. (a) HMGB1 concentration in the cardiac blood ( $\mathrm{n}=3$ ). (b) HMGB1 concentration in the tibia bone marrow ( $\mathrm{n}=4$ ). Error bars: Mean \pm SD. ${ }^{*} \mathrm{P}<0.01$ vs. sh-control. (C) Mechanical hyperalgesia results of each group. The test was performed every other day from POD1 to POD9 $(\mathrm{n}=8)$. Error bars: Mean \pm SD. ${ }^{*} \mathrm{P}<0.05$ vs. sh-control. (D) Excitation of sensory neurons determined by phosphorylated (p-)ERK1/2 expression in the DRGs of the sham, parental, sh-control, sh-HMGB1 SAS-injected mice by western blotting analysis. (a) Representative blot and (b) quantification with densitometry of p-ERK/ERK ( $n=3$ ). Error bars: Mean \pm SD. ${ }^{*}$ P<0.05 vs. sh-control. (E) Immunofluorescence analysis of DRGs. Upper panels, p-ERK1/2 (green); middle panels, CGRP (red); lower image, merged. Scale bar, $50 \mu \mathrm{m}$. HMGB1, high mobility group box 1; HNC, head and neck cancer; HNC-BP, HNC-associated bone pain; POD, postoperative day; CGRP, calcitonin gene-related peptide.

High mobility group box 1 (HMGB1) is a 25-kDa non-histone DNA binding protein that is generally distributed in the cell nucleus. The best-studied roles of HMGB1 are those in the immune system. Nuclear HMGB1 acts as a DNA chaperone 
A a
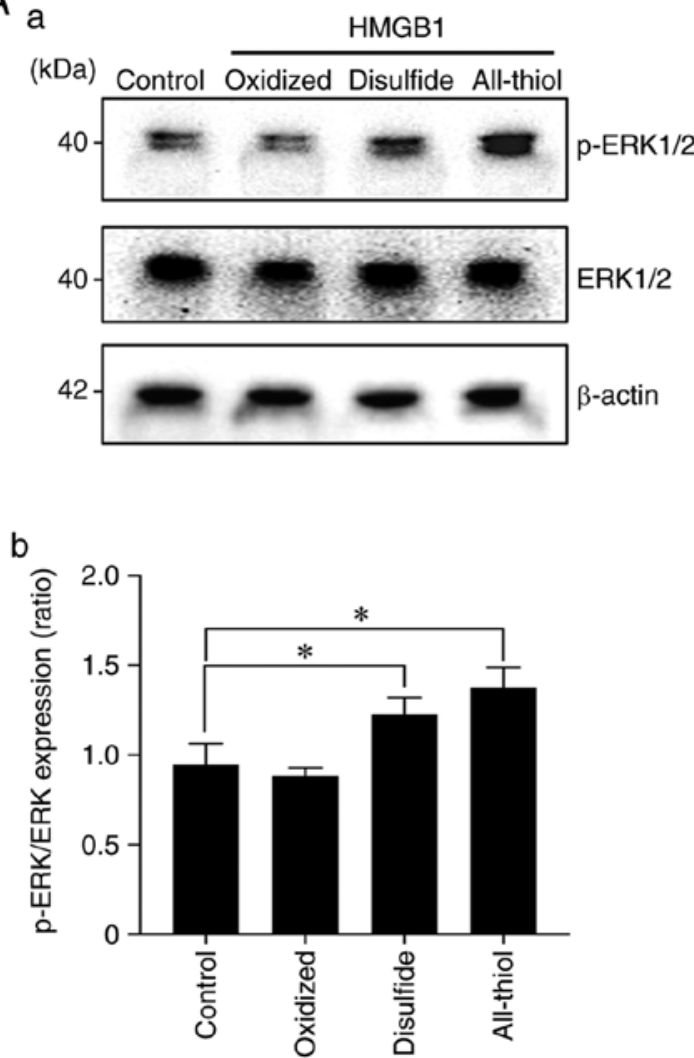
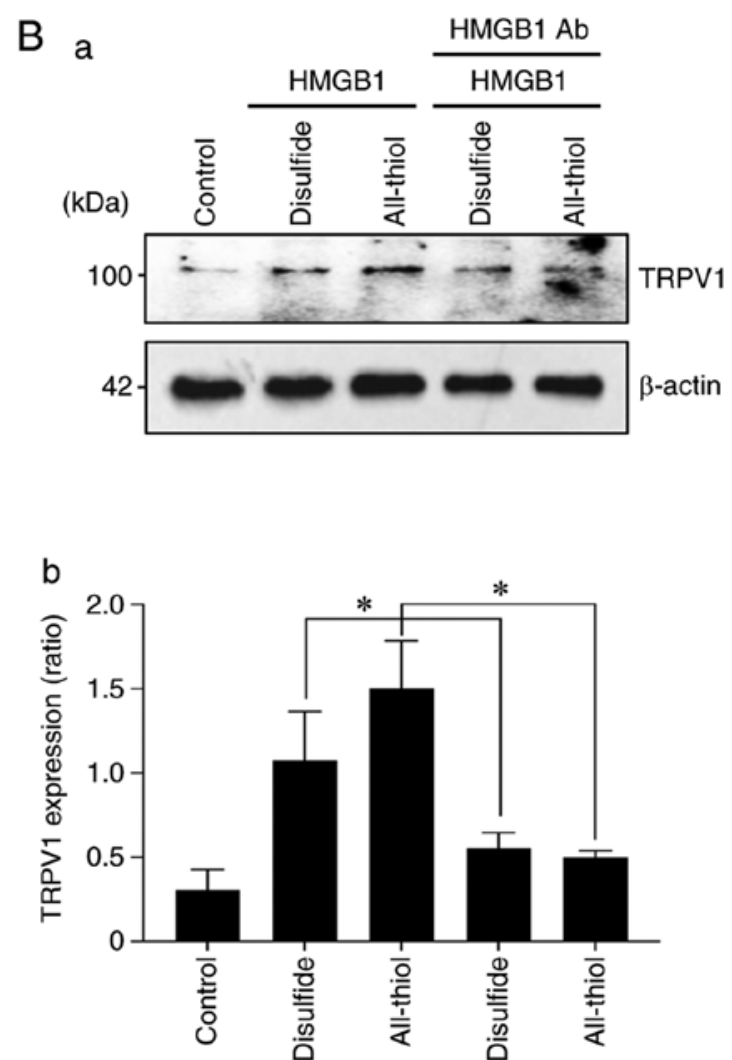

Figure 7. Relation of the redox status of HMGB1 in sensory neuron excitation. (A) Excitation of sensory neurons by different redux-statuses of HMGB1 as determined by phosphorylated (p-)ERK1/2 expression. (a) Representative blot (b) and quantification with densitometry of p-ERK/ERK (n=3). Error bars: Mean \pm SD. ${ }^{*} \mathrm{P}<0.05$ vs. control. (B) Expression of TRPV1 nociceptor in sensory neurons by different redux-status HMGB1 with/without HMGB1 neutralizing antibody (Ab). (a) Representative blot and (b) quantification ( $\mathrm{n}=3$ ). Error bars: Mean \pm SD. ${ }^{*} \mathrm{P}<0.05$ vs. disulfide, and vs. all-thiol. TRPVI, transient receptor potential vanilloid 1; HMGB1, high mobility group box 1 .

which regulates DNA repair and transcription (23). HMGB1 is also a damage-associated molecular pattern (DAMP), that is released from dead cells and dendritic cells $(24,25)$. HMGB1 is considered an inflammatory cytokine released from activated monocytes and macrophages $(26,27)$.

It has been reported that HMGB1 secreted from various cancer cells and the blood serum HMGB1 concentration are both correlated with poor patient prognosis $(28,29)$. Another study indicated that HMGB1 promotes sensory neuron sprouting and neuropathic pain in diseases such as pancreatitis, bladder pain, and arthritis (30). However, the role of HMGB1 in $\mathrm{HNC}$ bone pain (HNC-BP) remains unclear. Our present findings demonstrated that HNC SAS cells express HMGB1 in the cytoplasm and subsequently release HMGB1 to the extracellular space. In addition, our in vivo data revealed that HNC cells actively effuse HMGB1 to the extracellular space in bone marrow.

HMGB1 was found to evoke the influx of $\mathrm{Ca}$ in the neuron axis (31). Our present findings showed that SAS cells promote sensory neuron sprouting and elongation of the axis, and HMGB1 neutralizing antibody suppressed SAS conditioned medium-induced sensory neuron sprouting. These results indicate cancer-derived HMGB1 sensitization via increasing the length of sensory neuron axis.

Cytokines released from cancer promote osteoclastogenesis, and osteoclasts subsequently resorb the bone matrix by protons (32). The extracellular environment that is created by releasing protons from osteoclasts and by cancer contributes to the activation of sensory neurons and bone pain $(15,33)$. Osteoclasts release protons via a3V-ATPase, which is a V-type proton pump (34). Cancer cells released protons as lactic acid in a metabolic process (35).

The phosphorylation of ERK and CREB is a marker of sensory neuron excitation. Our present results demonstrated that SAS cell-derived HMGB1 increased the acid sensitivity of sensory neuron cells via the HMGB1 axis. Calcium influx is a direct indicator of cell excitation. Herein, the HMGB1 neutralizing antibody and RAGE antagonist similarly suppressed the cell excitation by proton stimulation followed by SAS conditioned medium co-incubation. We therefore speculate that HMGB1 from cancer cells enhances HNC-BP via acid sensitization.

As expected, the HMGB1 neutralizing antibody suppressed the cancer bone pain that was caused by SAS cell injection into mouse tibial bone. HMGB1 is released from various cells such as dendritic cells and necrotic cells. To investigate the importance of cancer-derived HMGB1 for HNC-BP but not other microenvironmental cells, we established HMGB1-knockdown SAS cells. The results showed that the HMGB1 level in the bone marrow was correlated with the HMGB1 expression in SAS cells. In addition, the HMGB1 knockdown in SAS cells decreased the sensory neuron excitation in vitro, and it decreased the HNC-BP in mice in vivo. This result indicated that the cancer-derived HMGB1 promoted HNC-BP. 


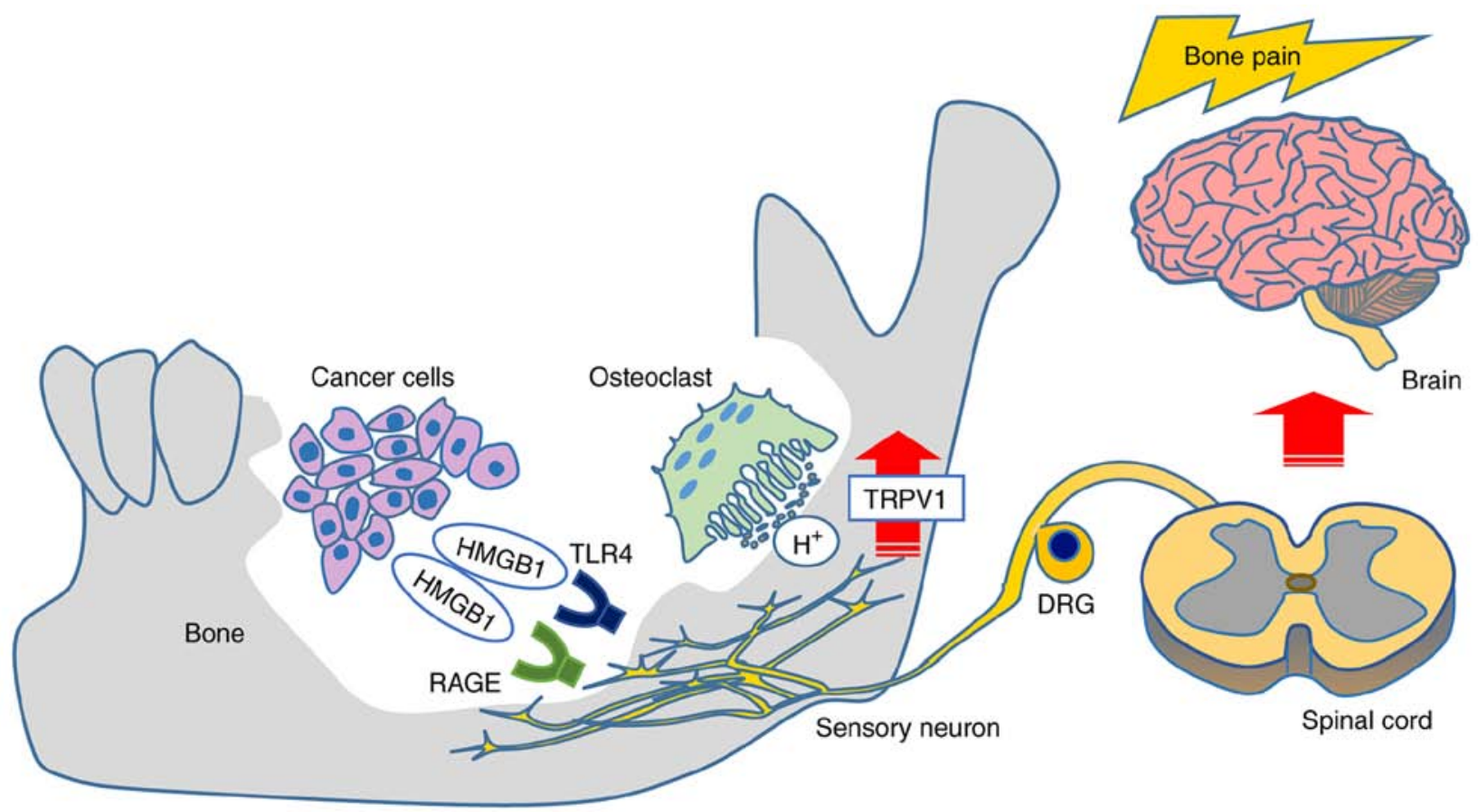

Figure 8. Schematic figure of the results of the present study. HMGB1 derived from HNC evokes HNC-BP via direct HMGB1 signaling and hypersensitization for the acid environment in sensory neurons. HMGB1, high mobility group box 1; HNC, head and neck cancer; HNC-BP, HNC-associated bone pain; RAGE, advanced glycation end products; TLR4, Toll-like receptor 4; DRG, dorsal root ganglia.

HMGB1 has two receptors, i.e., TLR4 and RAGE (20). The question of which receptor(s) play a critical role in HNC-BP remains unanswered. It was reported that different redox states of the three cysteines of HMGB1 endow it with mutually exclusive activities (36). Fully reduced HMGB1 binds mainly to RAGE, and disulfide HMGB1 binds to TLR4 (37). RAGE signaling is suspected to promote the phosphorylation of ERK, which is a marker of sensory neuron activation (38). The results of the present investigation demonstrated that compared to the partly oxidized form (disulfide HMGB1), the fully reduced form (All-thiol HMGB1) evoked sensory neuron excitation in vitro. In the in vivo experiment, the RAGE antagonist strongly suppressed HNC-BP compared to the TLR4 antagonist. Our results demonstrated that RAGE (and not TLR4) is critical for DRG excitation and HNC-BP.

In conclusion, our present findings demonstrated that the HMGB1 released from HNC cells promotes HNC bone pain via sensory neurons innervating bone marrow, acid sensing receptor TRPV1 activation, and a direct excitation of sensory neurons by RAGE signaling rather than by a TLR4 pathway (Fig. 8). Targeting these pathways may provide effective mechanism-based therapies for the control of HNC-BP, which is currently undertreated. Furthermore, TLR4 and RAGE antagonist are expected as newly therapeutic agents against diabetes mellitus, sepsis and rheumatoid arthritis that are also painful diseases (39). Future research for HMGB1 will improve the treatment methods of these diseases.

\section{Acknowledgements}

Not applicable.

\section{Funding}

This study was supported by a Grant-in-Aid for Young Scientists (\#18K17225 to TO) and a Grant-in-Aid for Scientific Research (B) (\#20H03889 to AS) from the Ministry of Education, Culture, Sports, Science, and Technology of Japan.

\section{Availability data and materials}

The datasets used and analyzed during the current study are available from the corresponding author on reasonable request.

\section{Authors' contributions}

TO conceived and designed the experiments. TN, TO and $\mathrm{KH}$ performed the experiments. TO and TN analyzed and interpreted the data. TN, SR, TO, KH, YK, SI, AS, KOno, KOba, and MM performed the data acquisition. TO and TN wrote the manuscript. TO, TS, SI and AS conducted the manuscript revision/review. All authors read and approved the final manuscript.

\section{Ethics approval and consent to participate}

All of the animal experimental protocols were approved by the Ethics Review Committee for Animal Experimentation of the Okayama University Graduate School of Medicine and Dentistry (OKU-2018701, 20/Nov/2018).

\section{Patient consent for publication}

Not applicable. 


\section{Competing interests}

The authors declare that they have no competing interests.

\section{References}

1. Zheng Y, Zhou H, Dunstan CR, Sutherland RL and Seibel MJ: The role of the bone microenvironment in skeletal metastasis. J Bone Oncol 2: 47-57, 2012.

2. Schmidt BL: The neurobiology of cancer pain. J Oral Maxillofac Surg 73 (Suppl 12): S132-S135, 2015.

3. Montazeri A: Quality of life data as prognostic indicators of survival in cancer patients: An overview of the literature from 1982 to 2008. Health Qual Life Outcomes 7: 102, 2009.

4. Viet CT and Schmidt BL: Biologic mechanisms of oral cancer pain and implications for clinical therapy. J Dent Res 91: 447-453, 2012.

5. Garg AD and Agostinis P: Cell death and immunity in cancer: From danger signals to mimicry of pathogen defense responses. Immunol Rev 280: 126-148, 2017.

6. Carballo M, Puigdomenech P and Palau J: DNA and histone $\mathrm{H} 1$ interact with different domains of HMG 1 and 2 proteins. EMBO J 2: 1759-1764, 1983.

7. Man LL, Liu F, Wang YJ, Song HH, Xu HB, Zhu ZW, Zhang Q and Wang YJ: The HMGB1 signaling pathway activates the inflammatory response in Schwann cells. Neural Regen Res 10: 1706-1712, 2015.

8. Das N, Dewan V, Grace PM, Gunn RJ, Tamura R, Tzarum N, Watkins LR, Wilson IA and Yin H: HMGB1 activates proinflammatory signaling via TLR5 leading to allodynia. Cell Rep 17: 1128-1140, 2016.

9. Sims GP, Rowe DC, Rietdijk ST, Herbst R and Coyle AJ: HMGB1 and RAGE in inflammation and cancer. Annu Rev Immunol 28 : 367-388, 2010.

10. Shao Y, Sha M, Chen L, Li D, Lu J and Xia S: HMGB1/TLR4 signaling induces an inflammatory response following high-pressure renal pelvic perfusion in a porcine model. Am J Physiol Renal Physiol 311: F915-F925, 2016.

11. Wang Y, Jiang Z, Yan J and Ying S: HMGB1 as a potential biomarker and therapeutic target for malignant mesothelioma. Dis Markers 2019: 4183157, 2019.

12. Sun S, Zhang W, Cui Z, Chen Q, Xie P, Zhou C, Liu B, Peng X and Zhang Y: High mobility group box-1 and its clinical value in breast cancer. Onco Targets Ther 8: 413-419, 2015.

13. Yi B, Williams PJ, Niewolna $M$, Wang $Y$ and Yoneda $T$ : Tumor-derived platelet-derived growth factor-BB plays a critical role in osteosclerotic bone metastasis in an animal model of human breast cancer. Cancer Res 62: 917-923, 2002.

14. Guise TA, Yin JJ, Taylor SD, Kumagai Y, Dallas M, Boyce BF, Yoneda T and Mundy GR: Evidence for a causal role of parathyroid hormone-related protein in the pathogenesis of human breas cancer-mediated osteolysis. J Clin Invest 98: 1544-1549, 1996.

15. Hiasa M, Okui T, Allette YM, Ripsch MS, Sun-Wada GH, Wakabayashi H, Roodman GD, White FA and Yoneda T: Bone pain induced by multiple myeloma is reduced by targeting V-ATPase and ASIC3. Cancer Res 77: 1283-1295, 2017.

16. Yoneda T, Hiasa M, Nagata Y, Okui T and White F: Contribution of acidic extracellular microenvironment of cancer-colonized bone to bone pain. Biochim Biophys Acta 1848: 2677-2684, 2015.

17. Wakabayashi H, Wakisaka S, Hiraga T, Hata K, Nishimura R, Tominaga $\mathrm{M}$ and Yoneda T: Decreased sensory nerve excitation and bone pain associated with mouse Lewis lung cancer in TRPV1-deficient mice. J Bone Miner Metab 36: 274-285, 2018

18. Ryumon S, Okui T, Kunisada Y, Kishimoto K, Shimo T, Hasegawa K, Ibaragi S, Akiyama K, Thu Ha NT, Monsur Hassan NM and Sasaki A: Ammonium tetrathiomolybdate enhances the antitumor effect of cisplatin via the suppression of ATPase copper transporting beta in head and neck squamous cell carcinoma. Oncol Rep 42: 2611-2621, 2019.

19. Ueno H, Matsuda T, Hashimoto S, Amaya F, Kitamura Y, Tanaka M, Kobayashi A, Maruyama I, Yamada S, Hasegawa $\mathrm{N}$, et al: Contributions of high mobility group box protein in experimental and clinical acute lung injury. Am J Respir Crit Care Med 170: 1310-1316, 2004.

20. Wu C, Ding X, Zhou C, Ye P, Sun Y, Wu J, Zhang A, Huang X, Ren L, Wang K, et al: Inhibition of intimal hyperplasia in murine aortic allografts by administration of a small-molecule TLR4 inhibitor TAK-242. Sci Rep 7: 15799, 2017.
21. Yang F, Wang Z, Zhang JH, Tang J, Liu X, Tan L, Huang QY and Feng H: Receptor for advanced glycation end-product antagonist reduces blood-brain barrier damage after intracerebral hemorrhage. Stroke 46: 1328-1336, 2015.

22. Hu XM, Yang W, Du LX, Cui WQ, Mi WL, Mao-Ying QL, Chu YX and Wang YQ: Vascular endothelial growth factor a signaling promotes spinal central sensitization and pain-related behaviors in female rats with bone cancer. Anesthesiology 131: $1125-1147,2019$.

23. Javaherian K, Liu JF and Wang JC: Nonhistone proteins HMG1 and HMG2 change the DNA helical structure. Science 199: 1345-1346, 1978.

24. Antoine DJ, Jenkins RE, Dear JW, Williams DP, McGill MR, Sharpe MR, Craig DG, Simpson KJ, Jaeschke H and Park BK: Molecular forms of HMGB1 and keratin-18 as mechanistic biomarkers for mode of cell death and prognosis during clinical acetaminophen hepatotoxicity. J Hepatol 56: 1070-1079, 2012.

25. Dumitriu IE, Baruah P, Valentinis B, Voll RE, Herrmann M, Nawroth PP, Arnold B, Bianchi ME, Manfredi AA and Rovere-Querini P: Release of high mobility group box 1 by dendritic cells controls $T$ cell activation via the receptor for advanced glycation end products. J Immunol 174: 7506-7515, 2005.

26. Lotze MT and Tracey KJ: High-mobility group box 1 protein (HMGB1): Nuclear weapon in the immune arsenal. Nat Rev Immunol 5: 331-342, 2005.

27. Jiang W, Li J, Gallowitsch-Puerta M, Tracey KJ and Pisetsky DS: The effects of CpG DNA on HMGB1 release by murine macrophage cell lines. J Leukoc Biol 78: 930-936, 2005.

28. Fang J, Ge X, Xu W, Xie J, Qin Z, Shi L, Yin W, Bian M and Wang H: Bioinformatics analysis of the prognosis and biological significance of HMGB1, HMGB2, and HMGB3 in gastric cancer. J Cell Physiol 235: 3438-3446, 2020.

29. Wu T, Zhang W, Yang G, Li H, Chen Q, Song R and Zhao L: HMGB1 overexpression as a prognostic factor for survival in cancer: A meta-analysis and systematic review. Oncotarget 7: 50417-50427, 2016.

30. Saleh A, Smith DR, Tessler L, Mateo AR, Martens C, Schartner E, Van der Ploeg R, Toth C, Zochodne DW and Fernyhough P: Receptor for advanced glycation end-products (RAGE) activates divergent signaling pathways to augment neurite outgrowth of adult sensory neurons. Exp Neurol 249: 149-159, 2013.

31. Allette YM, Due MR, Wilson SM, Feldman P, Ripsch MS, Khanna $R$ and White FA: Identification of a functional interaction of HMGB1 with receptor for advanced glycation end-products in a model of neuropathic pain. Brain Behav Immun 42: 169-177, 2014.

32. Teitelbaum SL: Bone resorption by osteoclasts. Science 289 : 1504-1508, 2000.

33. Caterina MJ, Schumacher MA, Tominaga M, Rosen TA, Levine JD and Julius D: The capsaicin receptor: A heat-activated ion channel in the pain pathway. Nature 389: 816-824, 1997.

34. Wu H, Xu G and Li YP: Atp6v0d2 is an essential component of the osteoclast-specific proton pump that mediates extracellular acidification in bone resorption. J Bone Miner Res 24: 871-885, 2009.

35. Hasegawa K, Okui T, Shimo T, Ibaragi S, Kawai H, Ryumon S, Kishimoto K, Okusha Y, Monsur Hassan NM and Sasaki A: Lactate transporter monocarboxylate transporter 4 induces bone pain in head and neck squamous cell carcinoma. Int J Mol Sci 19: 3317, 2018.

36. Janko C, Filipovic M, Munoz LE, Schorn C, Schett G, Ivanovic-Burmazovic I and Herrmann M: Redox modulation of HMGB1-related signaling. Antioxid Redox Signal 20: 1075-1085, 2014.

37. Yamasoba D, Tsubota M, Domoto R, Sekiguchi F, Nishikawa $H$, Liu K, Nishibori M, Ishikura $H$, Yamamoto T, Taga A and Kawabata A: Peripheral HMGB1-induced hyperalgesia in mice: Redox state-dependent distinct roles of RAGE and TLR4. J Pharmacol Sci 130: 139-142, 2016.

38. Balosso S, Liu J, Bianchi ME and Vezzani A: Disulfide-containing high mobility group box-1 promotes $\mathrm{N}$-methyl-D-aspartate receptor function and excitotoxicity by activating Toll-like receptor 4-dependent signaling in hippocampal neurons. Antioxid Redox Signal 21: 1726-1740, 2014.

39. VanPatten S and Al-Abed Y: High mobility group Box-1 (HMGb1): Current wisdom and advancement as a potential drug target. J Med Chem 61: 5093-5107, 2018.

This work is licensed under a Creative Commons Attribution-NonCommercial-NoDerivatives 4.0 International (CC BY-NC-ND 4.0) License. 